\title{
The Grain Security Assessment Based on Improved TOPSIS Model in Yunnan Province China
}

\author{
Kun Tong ${ }^{1, ~ *, ~ C h a o ~ Y a n g ~}{ }^{2}$ \\ ${ }^{1}$ Key Laboratory of Watershed Geographic Science, Nanjing Institute of Geography \& Limnology, Chinese Academy of Sciences, Nanjing, \\ China \\ ${ }^{2}$ Nanjing Guohuan Science and Technology Co Ltd, Nanjing, China
}

Email address:

tongkun0502@hotmail.com (Kun Tong), yangchao19851985@126.com (Chao Yang)

${ }^{*}$ Corresponding author

\section{To cite this article:}

Kun Tong, Chao Yang. The Grain Security Assessment Based on Improved TOPSIS Model in Yunnan Province China. International Journal of Food Science and Biotechnology. Vol. 4, No. 3, 2019, pp. 56-63. doi: 10.11648/j.ijfsb.20190403.11

Received: June 24, 2019; Accepted: July 16, 2019; Published: October 7, 2019

\begin{abstract}
Food security has become an important part of the security of all countries in the world, especially in a populous country like China. This paper analyzes the impact of different influencing factors on food security in Yunnan Province, and establishes an appropriate evaluation index system to analyze and evaluate the food security of Yunnan Province under the changing environment of 2001-2016. Firstly, the principal factors analysis method is used to divide the factors affecting food security in Yunnan Province into three levels: natural conditions, social development and technology level, and agricultural management level. Secondly, the entropy weight method is combined with the OWA operator to obtain the Yunnan Province. The main influencing factors are the total power of agricultural machinery, the amount of agricultural chemical fertilizer and the proportion of the primary industry's output value to GDP. Finally, using the improved gray correlation TOPSIS model, the food security in Yunnan Province has basically shown a trend of volatility growth since 2001. The calculation results show that since 2001, food security in Yunnan Province has shown a growth trend, the grain production has been effectively secured in Yunnan Province. In its three criteria levels, social development and technological level and agricultural management levels are steadily increasing, except for natural condition is volatile. In the future, Yunnan Province should reduce its dependence on mechanical power and fertilizer in the grain production process, further expand the development of green agriculture and organic agriculture, and ensure food safety production in many aspects.
\end{abstract}

Keywords: Grain Security, Grey TOPSIS Model, Entropy and OWA Weight

\section{Introduction}

In the 1970s, the United Nations grain and agriculture organization first proposed the concept of grain security and defined it as "Anyone can get grain that meets the needs of survival and health at any time." The 19th CPC national congress in 2017 proposed" ensuring national grain security and keeping Chinese rice bowls firmly in their hands" [1]. Grain security is an important part of national security. China's increasingly urbanized and wealthy population is driving a growing and changing demand for grain, which might not be met without significant increase in agricultural productivity and sustainable use of natural resources [2, 3]. Achieving grain system sustainability is a global priority [4].
In recent years, with the frequent occurrence of global extreme climate, global grain production is changing all the time, the issue of grain security once again becomes the focus of the public again and again. Especially some report said "In 12 of developing Asian's 22 countries, less than 5 percent of the population is projected to be grain insecure in 2027" [5]. So nowadays we should realize grain security may be the most important in our life.

Grain yield is complicated and affected by many factors. The Climate change, socio-economic, import capacity and subsidy program may driver the grain security [6-8]. Also models were used to verify it. The CAS model was used to analyze the maintaining grain security, showing the comprehensive plan combining technological innovation and policy control provides the best method of achieving grain 
security under the same climatic conditions [9]. A multidimensional coupling assessment model was set out to assess the grain security level and the warning status of China between 1995 and 2012, shows variety coordination may decrease the grain security [10]. The Analytic Hierarchy Process (AHP) was used to assess the grain security level in each APEC member economies, shows developed economies are in general more secured than developing economies [11].

On the whole, the impact on grain security at present is concentrated on the climate change and social-economic development. However, the situation in Yunnan province is quite special, because of the frequent occurrence of extreme weather, grain security changes are also relatively large. Therefore, it is of great significance to analyze the influencing factors of grain security in Yunnan province. This paper uses the TOPSIS evaluation model based on entropy-OWA weight to evaluate the grain security of Yunnan province, and analyzes the impact of natural factors, policy management, technology

level and other related factors on the grain security, in order to provide the basis for the improvement of grain crop yield.

\section{Research Area}

Located in the southwest border of China, Yunnan province lies between the $31^{\prime} \sim 106$ 'of longitude 97 and the 8' 29' of latitude 21, and the tropic of cancer crosses the southern part of Yunnan province. It covers a total area of 394,000 square kilometers, accounting for $4.1 \%$ of the total land area of the whole country, covering 16 states (cities) as shown in figure 1. the population of ethnic minorities accounts for one third of the total population of the province.

Yunnan is a mountainous plateau with a high terrain in the northwest and a low one in the southeast. From north to south, it falls step by step. There are more than 600 rivers, belonging to the six major rivers of Irrawaddy, nu river, lancang river, jinsha river, honghe river and pearl river.

$\mathrm{N}$

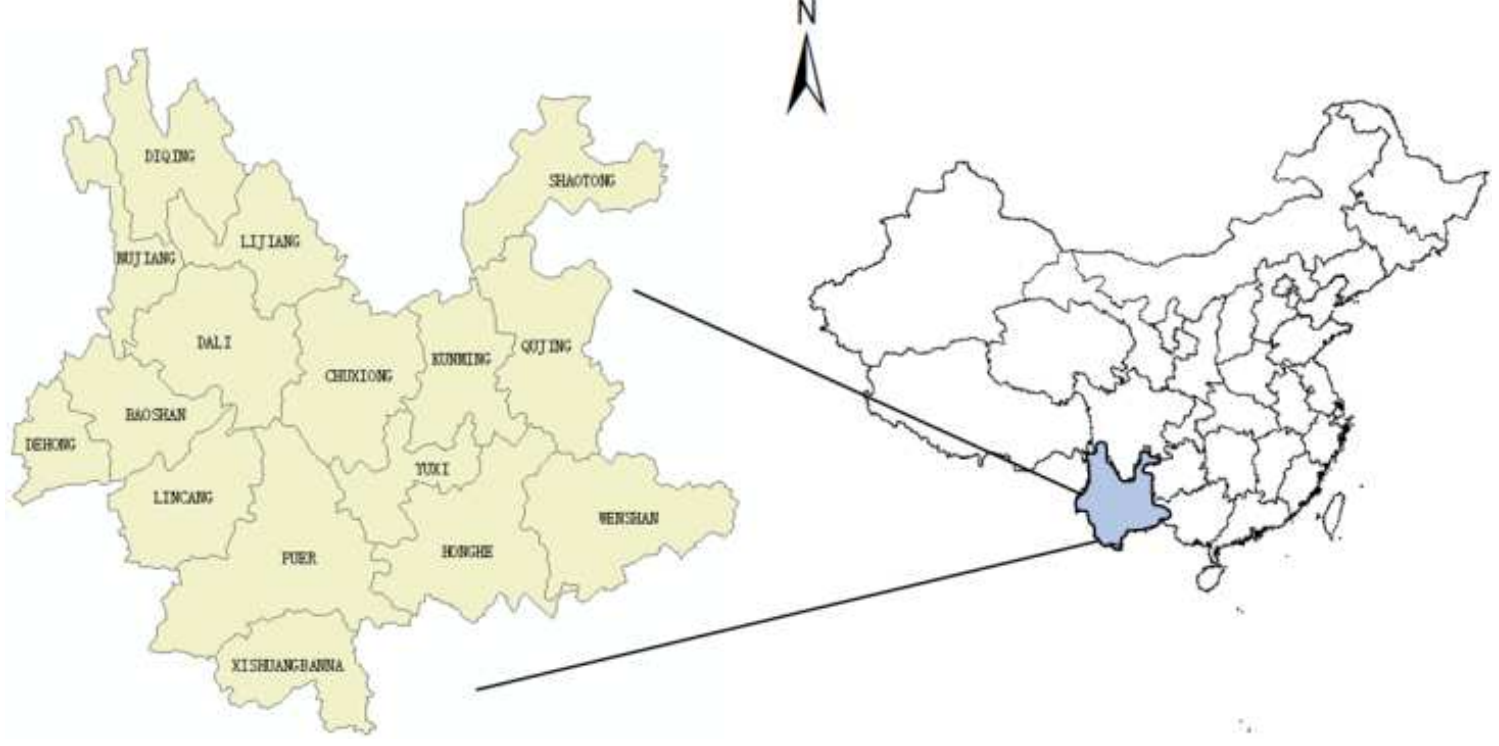

Figure 1. Schematic diagram of Yunnan province.

From 1997 to 2016, the annual average grain yield in Yunnan province was 15.96 million tons. It can be seen from figure 2, the grain yield of Yunnan province basically showed a growth trend, among which, from 2001 to 2002 and from 2005 to 2007 , the grain yield and planting area declined twice.

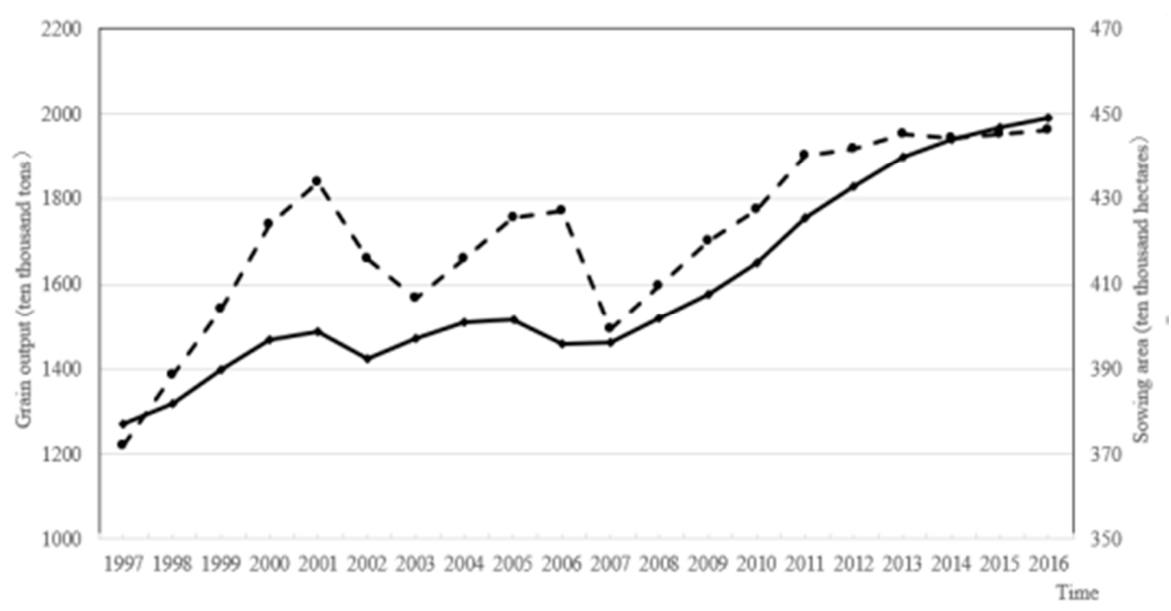

Figure 2. Yield of grain area in Yunnan province. 
In history, Yunnan is a province with disaster each year, due to the $94 \%$ of the land area of mountains and plateaus, if there is no rain the place is drought, if it rains then waterlogging, floods and drought often occur in turn, and the frequency is high, the natural disaster becomes intensity, long duration and the affected range, deep degree of loss. Figure 3 shows the crop disaster in Yunnan province from 2006 to 2010. It can be seen that the crops in Yunnan province damaged every year.

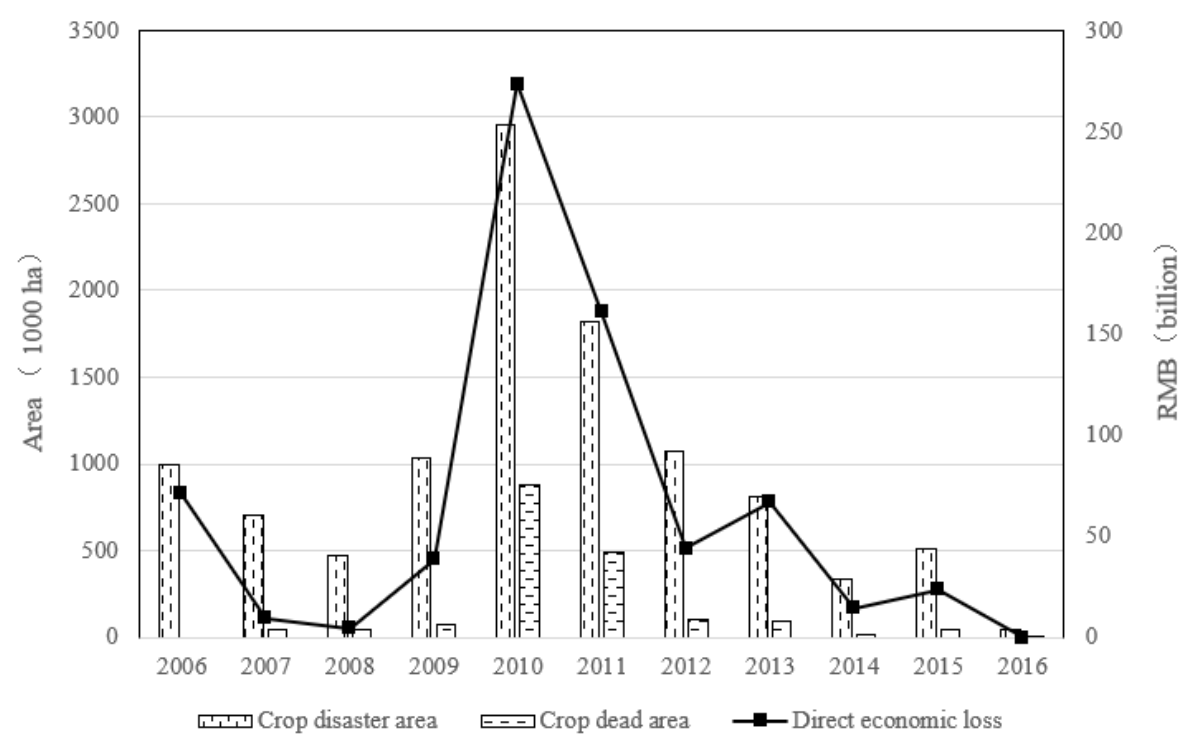

Figure 3. Crop damage in Yunnan province.

\section{Material and Methods}

\subsection{Single Factor Regression Analysis}

\subsubsection{Influencing Factor Sets}

Existing studies have shown that the yield of grain crops affected by many factors, such as precipitation, degree of agricultural mechanization, pesticide use, etc. Therefore, the influencing factors of grain yield are analyzed from four perspectives, including natural factors, social factors, technical factors and management factors.

1) Natural factors. Climate conditions (precipitation, temperature, humidity, evaporation, etc.), hydrological conditions, resource endowment, geographical location, etc., are the main factors affecting the yield of grain crops, among which the deterministic factors are geographical location, resource endowment, and uncertain factors are climatic conditions and hydrological conditions.

2) Economic factors. All kinds of resources are closely related to economic development. The imbalance of regional economic development has different impacts on water resources and land resources. At the same time, the industrial structure layout on the grain crop yield impact can not be ignored

3) Technical factors. The technical factors involved in grain yield mainly refer to the use of pesticides, degree of agricultural mechanization and so on. Generally speaking, the more advanced production technology, the higher the grain yield.

4) Management factors. There are many management factors related to grain output, such as national policies and management level. The regional management level has great influence on the grain yield.

Table 1. Complete set of influencing factors.

\begin{tabular}{|c|c|c|}
\hline Main types of & & Factors affecting the \\
\hline \multirow{2}{*}{ Natural factors } & climate & Average annual precipitation, average annual temperature, Proportion of disaster area \\
\hline & resources & The area of cultivated land, amount of water resources and per mu of solid irrigation \\
\hline Economic factors & State of the economy & primary industry value ratio to GDP, proportion of primary industry population to total, urbanization rate \\
\hline Technical factors & Technical types & Water-saving irrigation area ratio, large irrigated area ratio, agricultural mechanization power \\
\hline Management factors & Investment policy & $\begin{array}{l}\text { Proportion of agricultural expenditure, irrigation investment ratio, agricultural pesticide use, agricultural } \\
\text { fertilizer use }\end{array}$ \\
\hline
\end{tabular}

\subsubsection{Exploratory Factor Analysis}

This paper selects relevant data in China statistical yearbook and Yunnan statistical yearbook. Before factor analysis, linear testing of sample data, through constantly exploring calculation found that precipitation, water resource, irrigation water consumption per acre of farmland had a high correlation between agricultural water accounts for the proportion of the total water consumption; the arable land, inundated area of arable land proportion also correlation, therefore, determined the two factors of precipitation and explore the inundated area proportion, remove the rest. Through the validity of KMO and Bartlett test data of 
sphericity, the results show that KMO value is 0.58 and Bartlett test chi-square statistical value is 0.000 which shows in table 2, indicating that this statistical data is suitable for further analysis.

Table 2. KMO and Bartlett tests.

\begin{tabular}{lll}
\hline \multicolumn{2}{l}{ Kaiser meyer-olkin metric to sample enough } & 0.580 \\
& The approximate chi-square & 361.574 \\
Bartlett's test of sphericity & $\mathrm{df}$ & 91 \\
& $\mathrm{Sig}$ & 0.000 \\
\hline
\end{tabular}

Table 3. Principal component extraction.

\begin{tabular}{|c|c|c|c|c|c|c|}
\hline \multirow{2}{*}{ ingredients } & \multicolumn{3}{|c|}{ Initial eigenvalue } & \multicolumn{3}{|c|}{ Rotation sum of squares and loads } \\
\hline & A combined & $\%$ of the variance & Cumulative \% & A combined & $\%$ of the variance & Cumulative \% \\
\hline 1 & 8.481 & 60.576 & 60.576 & 8.432 & 60.232 & 60.232 \\
\hline 2 & 1.875 & 13.396 & 73.971 & 1.765 & 12.606 & 72.838 \\
\hline 3 & 1.522 & 10.870 & 84.842 & 1.680 & 12.003 & 84.842 \\
\hline 4 & 937. & 6.696 & 91.538 & & & \\
\hline 5 & 695. & 4.961 & 96.499 & & & \\
\hline 6 & 230 . & 1.642 & 98.141 & & & \\
\hline 7 & 138. & 982. & 99.123 & & & \\
\hline 8 & 063. & 453. & 99.575 & & & \\
\hline 9 & 049. & 349. & 99.925 & & & \\
\hline 10 & 006. & 044. & 99.968 & & & \\
\hline 11 & 003. & 024. & 99.993 & & & \\
\hline 12 & 001. & 005. & 99.997 & & & \\
\hline 13 & 000 . & 002. & 100.000 & & & \\
\hline
\end{tabular}

Table 4. Principal component analysis.

\begin{tabular}{llll}
\hline indicators & & F1 & F2 \\
\hline X1 & Agricultural fertilizer use & 0.994 & 0.020 \\
X2 & Proportion of primary industry population to all & 0.992 & 0.072 \\
X3 & Urbanization rate & 0.989 & 0.053 \\
X4 & Agricultural mechanization power & 0.985 & 0.027 \\
X5 & Water-saving irrigation area ratio & 0.985 & 0.016 \\
X6 & Agricultural pesticide use & 0.967 & 0.115 \\
X7 & Primary industry value ratio to GDP & 0.948 & 0.013 \\
X8 & Proportion of agricultural expenditure & 0.893 & 0.214 \\
X9 & Average annual temperature & 0.024 & 0.095 \\
X10 & disaster area ratio & 0.110 & 0.823 \\
X11 & Precipitation & 0.249 & 0.019 \\
X12 & Large irrigation area ratio & 0.052 & 0.097 \\
X13 & Irrigation investment ratio & 0.270 & 0.340 \\
\end{tabular}

Principal component factors were extracted according to the characteristic value greater than 1 , and the cumulative contribution rate of the first three factors reached $84.84 \%$ which can be seen in table 3 . We selected F1 as the first principal component, F2 as the second principal component and F3 as the third principal component, and transformed the original 14 indicators into three new ones.

The first principal component $\mathrm{F} 1$ has a large load at the $\mathrm{x} 1-\mathrm{x} 8$ and is all around 0.9 , which is mainly reflected in the level of technology level. The second principal component, F2, has large loads in X9, X10 and X11, describing the natural conditions. The third principal component, F3, has a large load in X12 and X13, which is reflected in the level of agricultural management.

\subsection{Weight Calculation}

TOPSIS is a method used in multi-objective decision-making in system engineering, which is widely used in regional economic development, network public opinion, land management and other research fields $[12,13]$. However, the traditional TOPSIS method has some defects: first, the determination of index weight is too subjective or objective; Second, more comprehensive sample data is needed, and the calculation of Euclidean distance is somewhat rigid [14]. In view of these deficiencies, the author adopts the combination weighting method of OWA operator and entropy weight method with the grey relational analysis method to improve the traditional TOPSIS method, and using the combination weighting method of subjective and objective to scientifically extract the weight level of the transformation index. In addition, the TOPSIS method was improved by using grey correlation to calculate the close value and comprehensive close value of each criterion layer, and the evaluation results of each criterion layer were further analyzed. Firstly combination weighting method can avoid the bias caused by simple subjective or objective weighting. Secondly, grey relational analysis method can solve the rigidity problem of less data and Euclidean distance. By improving the traditional TOPSIS method, the evaluation results can be more accurate and reliable.

For a long time, there are so many methods to determine the 
weighing values, such as analytic hierarchy process (AHP), the matter-element method and so on, but purely subjective empower vulnerable to the interference of human mind, objective empowerment can only rely on the mathematical relationship between data to illustrate the objective existence, therefore, this paper, by using entropy value method with OWA operator, get the combination of subjective and objective weights, so as to improve the scientific nature of the index weight calculation. The OWA operator theory was originally proposed by Yager [15], there are maximum and minimum operators, arithmetic mean operators, Olympic operators, arithmetic sequence operators [16]. In this paper, the arithmetic sequence operator is chosen to determine the position weight vector.

(1) OWA Operator Weight

First, the position weight is determined. Assume that $\mathrm{p}$ experts evaluate the $\mathrm{n}$ indicators, then the position weight vector $\mathrm{W}=\left(W_{1}, W_{2}, \cdots W_{p}\right)$ Is calculated as follows:

When $\mathrm{P}$ is odd:

$$
W_{i}=\left\{\begin{array}{l}
\frac{i}{((P+2) / 2)^{2}}, i \leq \frac{p+1}{2} \\
\omega_{p-(i-1)}, i>\frac{p+1}{2}
\end{array}\right.
$$

When $\mathrm{P}$ is even:

$$
W_{i}=\left\{\begin{array}{l}
\frac{i}{\left(\frac{p}{2}\right)^{2}+p / 2}, i \leq \frac{p}{2} \\
\omega_{p-(i-1)}, i>\frac{p}{2}
\end{array}\right.
$$

Secondly, the triangular fuzzy number method is used to assign the index weight to the expert evaluation. Assuming that there are $m$ evaluation objects and $n$ indicators, and the weight of indicator $\mathrm{j}$ is denoted as $\omega_{j}$. According to fuzzy mathematics, $\omega_{j}$ is mainly relies on the fuzzy judgment of the expert grading process. a, b and c represent the most pessimistic, probable and optimistic estimates of the evaluation indicators given by the experts, and constitute the triangular fuzzy matrix, using the weighted average operator $O(\otimes, \oplus)$, if integration, the specific operator formula is:

$$
O_{j}=\left(a_{j}+4 b_{j}+c_{j}\right) / 6, j=1,2, \cdots n
$$

The triangular fuzzy weight $\beta_{j}$ of indicator $\mathrm{j}$ is calculated as follows:

$$
\beta_{j}=O_{j} / \sum_{j=1}^{n} O_{j}
$$

Let $\beta_{j}$ stay in order from big to small $\beta_{1 j}, \beta_{2 j}, \cdots \beta_{p j}$. The weight vector of the position is aggregated with the newly generated weight sequence, and the final weight of index $\mathrm{j}$ is obtained, that is

$$
\omega_{j}=\sum_{i=1}^{p} W_{i} \cdot \beta_{i j}
$$

The weight of all evaluation indexes can be obtained by the analogy. Similarly, the weights of the dimension layers of different indicators are determined, and the weights of the criterion layer are obtained by combining the triangular fuzzy operators and the OWA position weights.

(2) Objective Weight Based on Entropy Weight Weighting Method

First, the index should be standardized calculated.

Standard processing formula of forward index:

$$
\dot{x_{l j}}=\frac{x_{i j}-\min \left(x_{i j}\right)}{\max \left(x_{i j}\right)-\min \left(x_{i j}\right)}, 1 \leq i \leq m, 1 \leq j \leq n
$$

Standardized treatment of reverse index:

$$
\dot{x_{l j}}=\frac{\max \left(x_{i j}\right)-x_{i j}}{\max \left(x_{i j}\right)-\min \left(x_{i j}\right)}, 1 \leq i \leq m, 1 \leq j \leq n
$$

Then, calculate the information entropy weight:

$$
\begin{gathered}
s_{j}=-\frac{1}{\ln (m)} \sum_{i=1, j=1}^{m, n}\left[\frac{\dot{x_{l \jmath}}+1}{\sum_{i=1, j=1}^{m, n}\left(\dot{x_{l \jmath}}+1\right)}\right]\left[\ln \left(\frac{\dot{x_{l \jmath}}+1}{\sum_{i=1, j=1}^{m, n}\left(\dot{x_{l \jmath}}+1\right)}\right)\right] \\
1 \leq i \leq m, 1 \leq j \leq n
\end{gathered}
$$

Weight is:

$$
\mu_{j}=\frac{1-s_{j}}{\sum_{j=1}^{n}\left(1-s_{j}\right)}
$$

\begin{tabular}{|c|c|c|c|c|}
\hline Rule layer & Index layer & OWA weights & Entropy weights & comprehensive weights \\
\hline \multirow{8}{*}{ Technological level } & Agricultural fertilizer use & 0.0987 & 0.0895 & 0.0941 \\
\hline & proportion of primary industry Population to all & 0.0803 & 0.1011 & 0.0907 \\
\hline & Urbanization rate & 0.0892 & 0.0677 & 0.0785 \\
\hline & agricultural mechanization power & 0.1134 & 0.0775 & 0.0954 \\
\hline & Water-saving irrigation area ratio & 0.0431 & 0.0672 & 0.0552 \\
\hline & Agricultural Pesticide use & 0.0205 & 0.1134 & 0.0670 \\
\hline & primary industry value ratio to GDP & 0.0644 & 0.1226 & 0.0935 \\
\hline & Average annual temperature & 0.0942 & 0.0744 & 0.0843 \\
\hline \multirow[t]{2}{*}{ Natural conditions } & disaster area ratio & 0.0550 & 0.0258 & 0.0404 \\
\hline & precipitation & 0.0894 & 0.0654 & 0.0774 \\
\hline \multirow{2}{*}{$\begin{array}{l}\text { Agricultural } \\
\text { management level }\end{array}$} & Large irrigation area ratio & 0.0714 & 0.0423 & 0.0569 \\
\hline & Irrigation investment ratio & 0.0692 & 0.0834 & 0.0763 \\
\hline
\end{tabular}

(3) Comprehensive Weight

$$
\theta_{i}=\varphi_{1} \omega_{i}+\varphi_{2} \mu_{i}
$$

$\varphi_{1}, \varphi_{2}$ is the combination coefficient $\varphi_{1}=\varphi_{2}=0.5$.

Through the above calculation, the weight vector of each indicator layer is obtained, as shown in table 5.

Table 5. Weight calculation. 
At present, the first factor influencing the grain security of Yunnan province is the power of agricultural mechanization. In 2016, every $\mathrm{hm}^{2}$ in Yunnan province ranked power of agricultural machinery is $5.36 \mathrm{KW}$, an increase of nearly 2.5 times compared with 2004. However, in Guizhou, Chongqing and other provinces, the intensity of agricultural machinery dependence is generally $0.5 \mathrm{kw} / \mathrm{hm}^{2}$ [17], showing that the dependence of the diesel energy is higher, therefore, the energy consumption in grain production increased, under the background of greenhouse gas emission reduction pressure, reduce the crop production of excessive dependence of mechanical power will help to ease the grain production process of the decline of the type of energy efficiency in the cycle [18], further ensure grain production security.

In addition, the fertilizers use is also one of the major impacts of grain production in Yunnan province. At present, a large amount of fertilizer application contributes significantly to increasing the grain yield. In 2016, the intensity of fertilizer application in Yunnan province was $0.37 \mathrm{t} / \mathrm{hm}^{2}$, which is higher than that of the 5 provinces and regions such as Qinghai, Guizhou, Heilongjiang, Gansu and Tibet in 2016, whose fertilizer use is lower than or close to $0.225 \mathrm{t} / \mathrm{hm}^{2}$ [19]. Excessive reliance on fertilizers for grain production also become a major influencing factor for environmental pollution of river basin water [20]. The resulting ecological pressure may be much higher than that of these provinces.

\subsection{Comprehensive Evaluation}

Combining the grey relational model with the TOPSIS model, the ideal distance between positive and negative and the grey relational model can be standardized, then the relative proximity can be corrected. The specific steps are as follows:

(1) Construct Decision Matrix

For a single year of evaluation, $m$ evaluation objects and $n$ indicators were set. After processing according to the standardized formulas (6) and (7), a standardized decision matrix was formed, which was denoted as D, i.e

$$
\mathrm{D}=\left|\begin{array}{ccc}
X_{11} & \cdots & X_{1 n} \\
\vdots & \cdots & \vdots \\
X_{m 1} & \cdots & X_{m n}
\end{array}\right|
$$

(2) Determine the Matrix Weighting and Negative Ideal Scheme

The matrix $\mathrm{D}$ is weighted to obtain the weighted normalized matrix, i.e

$$
\mathrm{QD}=\theta_{i} \times D
$$

The positive and negative ideal schemes are respectively denoted as $\lambda^{+}, \lambda^{-}$:

$$
\begin{aligned}
& \lambda^{+}=\left(\mathrm{QD}_{1}^{+}, \mathrm{QD}_{2}^{+}, \cdots, \mathrm{QD}_{n}^{+}\right) \\
& \lambda^{-}=\left(\mathrm{QD}_{1}^{-}, \mathrm{QD}_{2}^{-}, \cdots, \mathrm{QD}_{n}^{-}\right)
\end{aligned}
$$

(3) Calculate the Distance Between Each Evaluation Scheme and Positive and Negative Ideal Schemes $d_{i}^{+} 、 d_{i}^{-} \mathrm{I}$

$$
\begin{aligned}
& d_{i}^{+}=\sqrt{\sum_{j}^{n}\left(\mathrm{QD}_{j}-\lambda_{j}^{+}\right)^{2}} \\
& d_{i}^{-}=\sqrt{\sum_{j}^{n}\left(\mathrm{QD}_{j}-\lambda_{j}^{-}\right)^{2}}
\end{aligned}
$$

(4) The Grey Incidence Matrix of Each Evaluation Scheme and the Positive and Negative Project Scheme is Calculated $\gamma_{i j}^{+}, \gamma_{i j}^{-}$

$$
\begin{aligned}
& \gamma_{i j}^{+}=\frac{\min _{i} \min _{j}\left|\lambda_{j}^{+}-\mathrm{QD}_{j}\right|+d \max _{i} \max _{j}\left|\lambda_{j}^{+}-\mathrm{QD}_{j}\right|}{\left|\lambda_{j}^{+}-\mathrm{QD}_{j}\right|++d \max _{i} \max _{j}\left|\lambda_{j}^{+}-\mathrm{QD}_{j}\right|} \\
& \gamma_{i j}^{-}=\frac{\min _{i} \min _{j}\left|\lambda_{j}^{-}-\mathrm{QD}_{j}\right|+d \max _{i} \max _{j}\left|\lambda_{j}^{-}-\mathrm{QD}_{j}\right|}{\left|\lambda_{j}^{-}-\mathrm{QD}_{j}\right|++d \max _{i} \max _{j}\left|\lambda_{j}^{-}-\mathrm{QD}_{j}\right|}
\end{aligned}
$$

Where $d$ is the difference coefficient, $d \in[0,1]$ In general $\mathrm{d}=0.5$.

Then the grey relational value of each evaluation scheme and ideal scheme is:

$$
\begin{aligned}
& \gamma_{i}^{+}=\frac{1}{n} \sum_{j=1}^{n} \gamma_{i j}^{+} \\
& \gamma_{i}^{-}=\frac{1}{n} \sum_{j=1}^{n} \gamma_{i j}^{-}
\end{aligned}
$$

(5) Standardized Treatment of Distance D and Correlation Degree R

$$
\begin{aligned}
D_{i}^{+} & =\frac{d_{i}^{+}}{\max _{i} d_{i}^{+}} \\
D_{i}^{-} & =\frac{d_{i}^{-}}{\max _{i} d_{i}^{-}} \\
R_{i}^{+} & =\frac{\gamma_{i}^{+}}{\max _{i} \gamma_{i}^{+}} \\
R_{i}^{-} & =\frac{\gamma_{i}^{-}}{\max _{i} \gamma_{i}^{-}}
\end{aligned}
$$

(6) Relative Posting Progress Calculation

Combing the distance after the standardization and grey correlation degree to calculate the relative closeness degree between the evaluation schemes and the positive, negative ones. Merged as follows:

$$
\begin{aligned}
& B_{i}^{+}=\frac{1}{2} D_{i}^{+}+\frac{1}{2} R_{i}^{+} \\
& B_{i}^{-}=\frac{1}{2} D_{i}^{-}+\frac{1}{2} R_{i}^{-}
\end{aligned}
$$

The relative closeness degree between the revised evaluation schemes and the positive and negative ideal schemes is:

$$
\pi_{i}=\frac{B_{i}^{-}}{B_{i}^{+}+B_{i}^{-}}
$$

The closeness degree of each criterion layer and ideal 
scheme is calculated, as shown in table 6 .

Table 6. Calculation table of ideal solution proximity

\begin{tabular}{|c|c|c|c|c|c|}
\hline year & $\begin{array}{l}\text { technological level } \\
\text { closeness }\end{array}$ & $\begin{array}{l}\text { Natural condition } \\
\text { closeness }\end{array}$ & $\begin{array}{l}\text { agricultural management } \\
\text { level closeness }\end{array}$ & $\begin{array}{l}\text { Integrated ideal } \\
\text { solution approximation }\end{array}$ & $\begin{array}{l}\text { Comprehensive } \\
\text { ranking }\end{array}$ \\
\hline 2001 & 0.4028 & 0.5525 & 0.2588 & 0.4160 & 12 \\
\hline 2002 & 0.3981 & 0.5102 & 0.4402 & 0.4164 & 11 \\
\hline 2003 & 0.3799 & 0.3995 & 0.5184 & 0.3944 & 16 \\
\hline 2004 & 0.4186 & 0.3607 & 0.4600 & 0.4120 & 13 \\
\hline 2005 & 0.3821 & 0.5803 & 0.5400 & 0.4308 & 9 \\
\hline 2006 & 0.3561 & 0.4297 & 0.6192 & 0.3969 & 15 \\
\hline 2007 & 0.3923 & 0.4191 & 0.3834 & 0.3977 & 14 \\
\hline 2008 & 0.4383 & 0.4300 & 0.3329 & 0.4254 & 10 \\
\hline 2009 & 0.4833 & 0.3896 & 0.2165 & 0.4368 & 8 \\
\hline 2010 & 0.4947 & 0.6535 & 0.2228 & 0.4959 & 6 \\
\hline 2011 & 0.5426 & 0.0859 & 0.2136 & 0.4416 & 7 \\
\hline 2012 & 0.5952 & 0.3822 & 0.4288 & 0.5436 & 3 \\
\hline 2013 & 0.5605 & 0.3926 & 0.3846 & 0.5163 & 5 \\
\hline 2014 & 0.5797 & 0.4477 & 0.3329 & 0.5395 & 4 \\
\hline 2015 & 0.5946 & 0.4891 & 0.9046 & 0.6015 & 2 \\
\hline 2016 & 0.5976 & 0.6072 & 1.0000 & 0.6206 & 1 \\
\hline
\end{tabular}

\section{Result and Discussion}

On the whole, the comprehensive closeness degree of Yunnan province is increasing year by year, and the safety degree of grain production is higher and higher. From 2001 to 2016, the value technological proximity basically showed the characteristics of increasing year by year. In its index layer, the main factor was the power of agricultural machinery. The higher the agricultural machinery force, the safer grain production, which meant that in future grain production, more attention should be paid to the driving role of technological innovation. Criterion layer under natural conditions is close to the degree of volatility in the dynamic, the reason mainly is the natural conditions is difficult to control, such as a long time, the influence factors of water resources is important in the process of grain production, but around 2009 years of drought, caused the grain output has fallen sharply in Yunnan province, therefore, in the process of production in the future, the more possible dry crops is also one of the future transformation of grain safety in production in Yunnan province. From 2001 to 2016, the close value of agricultural management in Yunnan province also showed an upward trend, indicating that in recent years, under the situation of water-saving irrigation and construction of large-scale irrigated areas continuously advocated by the state and government, the agricultural management level of Yunnan province has been improved, and grain security has also been guaranteed.

\section{Conclusion}

Using principal component analysis (pca), this paper constructs an evaluation index system of safety guarantee in Yunnan province from three aspects: natural factors, agricultural management level and technological level. The grain security of Yunnan province from 2004 to 2016 was systematically evaluated by using the improved TOPSIS method of entropy -OWA operator and grey correlation. The conclusion is as follows:

1) The contribution from the index, the future of Yunnan province should be devoted to improve the overall grain production capacity, continuing to reduce excessive dependence on energy grain production process, as well as expand green agriculture and organic agriculture in the proportion of primary industry, solve the problem of grain production, damage to the ecological environment, to promote grain security improving.

2) According to the change trend of time series, the grain security of Yunnan province was gradually increasing from 2004 to 2016, especially after 2010, which indicated that with the great attention of the state and government, the grain security of Yunnan province was effectively guaranteed.

\section{Acknowledgements}

This work was supported by "One-Three-Five" Strategic Planning of Nanjing Institute of Geography and Limnology, Chinese Academy of Sciences (Grant No. NIGLAS2017GH07).

\section{References}

[1] Grain and Agriculture Organization of the United States. The State of Grain Insecurity in the World, 2013: The Multiple Dimensions of Grain Security. Grain and Agricultural Organization of the United Nations, 2013.

[2] 19 spirit into the central enterprise / cofco group: to safeguard national grain security, the Chinese people's rice bowl firmly in their hands. http://news.cctv.com/2017/11/21/ARTIlkDiUTlET47Ths0aAa 4N171121.shtml.

[3] Lu, Y., Jenkins, A., Ferrier, R. C., Bailey, M., Gordon, I. J., Song, S. \& Feng, Z. (2015) Addressing China's grand challenge of achieving grain security while ensuring environmental sustainability. Science advances, 1 (1), e1400039. 
[4] Garnett, T. (2014) Three perspectives on sustainable grain security: efficiency, demand restraint, grain system transformation. What role for life cycle assessment? Journal of Cleaner Production, 73: 10-18.

[5] Meade, B., \& Thome, K. (2017) International grain security assessment, 2017-2027. Assessment, 2017, 2027.

[6] Rosen, S., Meade, B., Fuglie, K., \& Rada, N. (2016) International grain security assessment, 2014-2024. Economic Research, 2014, 2024.

[7] Aggarwal, P. K., Thornton, P. K., Dunnett, A., Shirsath, P. B., Joshi, P. K., Pal, B. D., ... \& Ghosh, J. (2018) Multi-objective land use allocation modelling for prioritizing climate-smart agricultural interventions.

[8] Yi, F., Sun, D., \& Zhou, Y. (2015) Grain subsidy, liquidity constraints and grain security-Impact of the grain subsidy program on the grain-sown areas in China. Grain policy, 50: 114-124.

[9] Cheng, K., Fu, Q., Li, T., Jiang, Q., \& Liu, W. (2015) Regional grain security risk assessment under the coordinated development of water resources. Natural Hazards, 78 (1): 603-619.

[10] Wu, J., Zhang, J., Wang, S., \& Kong, F. (2016) Assessment of grain security in China: A new perspective based on production-consumption coordination. Sustainability, 8 (3): 183.

[11] Eicher-Miller, H. A., \& Zhao, Y. (2018) Evidence for the age-specific relationship of grain insecurity and key dietary outcomes among US children and adolescents. Nutrition research reviews, 31 (1): 98-113.

[12] Wu Sen, Li Hujie, Chen Guohui, et al. (2016) Sensitivity analysis of regional landslide impact factors based on contribution rate weighting method. Chinese Journal of Geological Hazard and Control, pp26-31.

[13] Qiao Jianping, Shi Lili, Wang Meng. (2008) Landslide risk zoning based on overlapping weights of contributions. Geology, 27 (11): 1787-1794.

[14] Qiao Jianping, WANG Meng. (2011) Research on landslide hazard zoning with overlapping weights of contributions. Journal of Natural Disasters, 20 (2): 8-13.

[15] Yager R R. (1996) Quantifier guided aggregation using OWA operators. International Journal of Intelligent Systems, 11 (1): 49-73.

[16] Liu Yumin, Kang Qianqian, Wang Ning. (2016) Research on Airport Service Quality Evaluation Method Based on OWA Operator. Management Modernization, pp, 76-79.

[17] Jiang Junchao, Zhao Liangshi, Zheng Defeng. (2018) Analysis of Grain Security and Its Provincial Contribution in Mainland China from 1998 to 2016. Journal of Liaoning Normal University (Natural Science Edition), (41): 395-402.

[18] Dong Ying, Mu Yueying. (2014) Changes in China's Grain Production Efficiency and Its Influencing Factors — Analysis Based on Energy Perspective. Journal of Northwest A\&F University (Social Science Edition), (6): 103-111.

[19] SHI Changliang, GUO Wei, ZHU Junfeng. (2016) Evaluation and Influencing Factors of Fertilizer Excessive Application in China's Grain Production. Journal of Agricultural Modernization Research, 37 (4): 671-679.

[20] ZHOU Liang, XU Jian-gang, CAI Bei-xi, et al. (2014) Temporal and spatial changes of grain production and fertilizer consumption in the Huaihe River Basin and their impact on water environment. JOURNAL OF NATURAL RESOURCES, 29 (6): 1053-1064. 